\title{
OS MECANISMOS DE PARTICIPAÇÃO SOCIAL DA CÂMARA DE VEREADORES DE CACHOEIRA DO SUL E OS OBJETIVOS DA GOVERNANÇA PÚBLICA
}

\section{OS MECANISMOS DE PARTICIPAÇÃO SOCIAL DA CÂMARA DE VEREADORES DE CACHOEIRA DO SUL E OS OBJETIVOS DA GOVERNANÇA PÚBLICA}

\author{
Igor Noronha de Freitas* \\ Nelson Guilherme Machado Pinto ${ }^{* *}$
}

\section{RESUMO}

A Constituição de 1988, a chamada "Constituição Cidadã", veio irradiando efeitos nas Constituições Estaduais e Leis Orgânicas Municipais no que toca à participação social nas decisões governamentais e caminha paralelamente ao reconhecimento de determinada coletividade à importância desse protagonismo social, na proporção da transparência e da acessibilidade dadas pelos representantes ou governantes a esses mecanismos. Na Câmara de Vereadores de Cachoeira do Sul, existem mecanismos à disposição dos munícipes que dialogam com essa participação social. O trabalho faz a análise de cada um deles, objetivando mensurá-los e verificar a presença de iniciativas de governança pública. A problemática que surge nesse contexto é, se com essas formas de participação social, os conceitos de governança são alcançados. A fundamentação teórica foi erigida com base em três pilares: Governança, sob o aspecto da transparência; Democracia Participativa, pelo exercício da cidadania; e na Gestão Pública Municipal, sob o viés do papel do menor ente de nossa federação e como a participação opera nas decisões políticas e administrativas. Os resultados mostram cada instrumento de participação dentro do espaço delimitado pelo estudo, os anos de 2017 e 2018, em função do empirismo proposto, o exercício do mandato parlamentar na $17^{\mathrm{a}}$ legislatura. As considerações finais trazem a análise quantitativa desses mecanismos de participação e a partir disso é feita uma análise sobre o cumprimento dos objetivos propostos, bem como se apresentam as respostas ao problema apresentado neste estudo

Palavras-chave: Governança. Democracia Participativa. Gestão Pública Municipal.

\section{ABSTRACT}

The 1988 Constitution, the so-called "Citizen Constitution", has radiated effects on the State Constitutions and Municipal Organic Laws with regard to social participation in government decisions and this goes hand in hand with the recognition of a certain collectivity for the importance of this social role, in proportion to the transparency and the accessibility given, by representatives or governments, to these mechanisms. In the City Council of Cachoeira do Sul, there are mechanisms available to citizens who dialogue with this social participation. The work analyzes each of them, aiming to measure them and verify the presence of public governance initiatives. The problem that arises in this context is whether with these forms of social participation the concepts of governance

\footnotetext{
* Agente Administrativo na Universidade Estadual do Rio Grande do Sul - UERGS, Advogado, inscrito na OAB/RS sob o n ${ }^{\circ}$ 75648, Mestrando do Programa de Pós-Graduação em Gestão das Organizações Públicas da UFSMP). E-mail: igornoronhadefreitas@yahoo.com.br

Professor Adjunto do Departamento de Administração UFSM, professor do Programa de Pós-Graduação em Organizações Públicas da UFSM e Doutor em Administração pela UFSM. E-mail: nelguimachado@ hotmail.com.
}

Revista Eletrônica do Alto Vale do Itajaí - REAVI, v.09, nº 14, p. 082-096, ago. 2020.

ISSN: 2316-4190, DOI 10.5965/2316419009142020082 
are achieved. The theoretical foundation was based on three pillars: Governance, under the aspect of transparency, Participatory Democracy, through the exercise of citizenship, and Municipal Public Management, under the bias of the role of the minor entity in our federation and how participation operates in political and administrative decisions. The results show each instrument of participation within the space delimited by the study, the years 2017 and 2018, depending on the proposed empiricism, the exercise of parliamentary mandate in the 17th legislature. The final considerations bring the quantitative analysis of these participation mechanisms and from that an analysis is made on the fulfillment of the proposed objectives, as well as the answers to the problem presented in this study are presented.

Keywords: Government. Democracy Participation. Municipal Public Management.

Data de submissão: 10 de dezembro de 2019.

Data de aprovação: 15 de abril de 2020.

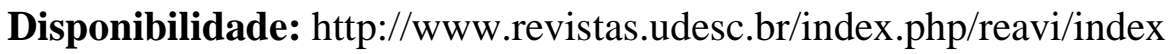

\section{INTRODUÇÃO}

Segundo Avritzer (2013, p. 11), já é lugar comum identificar o forte avanço da participação social com a promulgação da Constituição de 1988 e com as legislações infraconstitucionais que lhe seguiram. De acordo com Schier e Melo (2017, p. 129) "foi um importante momento de ruptura e, em virtude do cenário anterior ter sido carregado de restrições e privações à participação popular, a Constituição Cidadã” traz vários dispositivos que consagram liberdades antes suprimidas. Este processo irradiou efeitos nas Constituições Estaduais e Leis Orgânicas Municipais, que trazem vários mecanismos de participação popular. Esta participação dar-se-á na medida do reconhecimento de determinada coletividade à importância desse protagonismo social, na proporção da transparência e da acessibilidade dadas pelos representantes ou governantes, a esses mecanismos. Para Lock (2012, p. 35), "a participação do cidadão na rede social política, depende, principalmente, do amadurecimento da consciência cidadã".

Em Cachoeira do Sul, cidade do centro do Estado do Rio Grande do Sul (aproximadamente noventa mil habitantes), a lei orgânica do município, promulgada em 1990, prevê alguns desses mecanismos, ampliados pelo regimento interno da câmara municipal de vereadores e por resoluções da casa, colocando à disposição do munícipe vários fóruns e ferramentas de participação social nos assuntos da mencionada cidade.

Partindo do empirismo proposto para a elaboração do presente trabalho, a partir da experiência como integrante do poder legislativo na citada municipalidade, o texto analisa cada um desses mecanismos, da previsão legal à utilização pela população, na delimitação no tempo proposta, nos anos de 2017 e 2018, a primeira metade da $17^{\mathrm{a}}$ legislatura, atualmente em curso.

Saber se a partir da aplicabilidade dessas normas se está promovendo a governança pública é o que este estudo tem por objetivo. Na fundamentação teórica, três são os pilares para o seu desenvolvimento. A Governança, principalmente a aplicável à Administração Pública, no que toca à transparência. Na Democracia Participativa, o exercício da cidadania será o enfoque e de Gestão 
Pública Municipal, sob o viés do papel do menor ente de nossa federação. As considerações finais vão cuidar da análise quantitativa desses mecanismos de participação e, a partir dessa forma de levantamento de dados, procurar-se-á mensurar se os objetivos da governança pública foram atendidos, de onde se extrai a problemática do estudo: seriam esses mecanismos de participação suficientes e hábeis na promoção da governança pública?

Do cumprimento dos objetivos do estudo e das respostas à problemática é que se evidencia a importância da presente pesquisa. A governança, um conceito originário da iniciativa privada, quando corretamente incorporado à Administração Pública envolve o cidadão, promove interação e trabalhada com os conceitos de democracia participativa, faz do destinatário final das políticas públicas partícipe do processo de elaboração e implementação. $\mathrm{O}$ pioneirismo do assunto, ainda não abordado no cenário local, é outra justificativa para o desenvolvimento do trabalho, de onde se verifica a possibilidade do presente método ser replicado quando observado outro cenário.

\section{FUNDAMENTAÇÃO TEÓRICA}

As bases teóricas nas quais se sustenta este trabalho estão inseridas em um conceito maior, a gestão social. De acordo com Cançado, Pereira e Tenório (2015, p.9), neste contexto "busca-se uma nova esfera pública que consiga aproximar a população da política". Os autores ainda falam da necessidade de "um espaço onde as pessoas privadas se encontrem em um espaço público a fim deliberarem sobre suas necessidades e futuro". Assim, é que serão abordadas teorias sobre governança pública, democracia participativa e gestão pública municipal.

\subsection{GOVERNANÇA PÚBLICA}

Segundo Ramos, Vieira e Paraboni (2017, p.2) “desde sua redemocratização a sociedade brasileira nunca debateu tanto o tema da produtividade e a qualidade dos processos e decisões que envolvem os entes estatais". Os autores ainda mencionam que este processo "propõe introduzir no setor governamental as mudanças de valores e comportamentos indispensáveis à Administração Pública na promoção do desenvolvimento do Estado para o bem-estar social" (2017, p.3). Para Cavalcante e Pires (2018) isto difere do padrão convencional, fazendo surgir a governança pública, a partir das relações entre o governo, o mercado e a sociedade civil.

De acordo com Pinto e Reisdorfer (2015, p.30) "a governança pública é a capacidade do setor público, na figura de ação do Estado, em formular e programar políticas públicas para que ocorram a consecução das metas coletivas da sociedade. Portanto, essa governança está preocupada com a gestão dos recursos públicos”. Nesse sentido, a diferença entre governança e governabilidade, trazida por Siqueira e Rosolen (2018) é importante para a gestão pública. Para os autores "enquanto a governabilidade consiste na capacidade política do Estado" (2018, p. 668), a legitimidade através de condições estruturais, políticas, econômicas e sociais, a governança é a capacidade de execução das políticas públicas de governar com eficiência na sua implementação.

É possível verificar a aplicabilidade desses conceitos, segundo Ckagnazaroff (2017). Para o autor é possível identificar duas preocupações, tanto em países desenvolvidos quanto em países em desenvolvimento: uma voltada à eficiência e à eficácia das suas respectivas administrações públicas, por privatizações ou parcerias; por meio de estratégias relacionadas às redes de políticas públicas, à

Revista Eletrônica do Alto Vale do Itajaí - REAVI, v.09, n 14, p. 082-096, ago. 2020.

ISSN: 2316-4190, DOI 10.5965/2316419009142020082 
descentralização e à participação cidadã. A outra se materializa na preocupação com a transparência, prestação de contas e representatividade de tais articulações, uma vez que esses processos envolvem recursos públicos e buscam responder às demandas sociais.

Segundo Haret, Silveira e Alves (2016) a soberania popular, como princípio constitucional "é uma premissa dialógica entre a sociedade e o Estado, promovendo uma real participação de todos os envolvidos no processo de concretização do poder e solidificação da democracia popular". Esse diálogo, com interação e participação na iniciativa privada, é chamado de governança. A expressão governança pública encontra paradigma na corporativa. Segundo o Instituto Brasileiro de Governança Corporativa - IBGC (2009, p. 19):

"É o sistema pelo qual as organizações são dirigidas, monitoradas e incentivadas, envolvendo os relacionamentos entre proprietários, Conselho de Administração, Diretoria e órgãos de controle. As boas práticas de Governança Corporativa convertem princípios em recomendações objetivas, alinhando interesses com a finalidade de preservar e otimizar o valor da organização, facilitando seu acesso a recursos e contribuindo para sua longevidade."

Ainda, segundo o IBGC, os princípios básicos de governança corporativa são a transparência, a equidade, a prestação de contas e a responsabilidade corporativa. Segundo Nobre et al (2017, p.73) "o tema transparência pública está em constante evidência, seja por meio dos dispositivos legais em que estão inseridos, como também pela pressão social por maiores esclarecimentos de informações sobre recursos públicos”. O IBGC vai dizer que esta transparência dialoga com a disponibilidade às partes interessadas de informações que sejam de seu interesse e não apenas àquelas impostas por leis ou regulamentos, e que a adequada transparência resulta em um clima de confiança. A equidade é caracterizada pelo tratamento justo de todos os interessados (stakeholders), não existindo espaço para atos discriminatórios de qualquer ordem. Prestação de contas (accountability) é o processo através do qual as entidades e os gestores públicos são responsabilizados pelas próprias decisões e ações, a resposta a uma responsabilidade conferida, conforme Sobreira e Júnior (2017).

Por fim, Rodrigues e Dalongaro (2018, p.5) mencionam que "a responsabilidade corporativa está relacionada à ética. A empresa deve, além de respeitar as leis de seu país, ter uma definição clara de seus valores e princípios éticos, por isso, deve garantir a sustentabilidade da empresa, com vistas à sua longevidade". Assim, segundo Ckagnazaroff (2017), "governança é um padrão ou estrutura que emerge em um determinado sistema político-social como o resultado comum de intervenções de todos os atores envolvidos/interessados". Sem a presença clara e consolidada dos princípios elementares de governança a participação social fica prejudicada. A cidadania positiva não se constitui somente na presença destes princípios, mas também quando o cidadão se vê partícipe do processo de elaboração e decisões sobre as políticas públicas.

\subsection{DEMOCRACIA PARTICIPATIVA}

A teoria geral do estado estuda toda sua dinâmica, desde a origem, formatação organizacional, até o funcionamento e finalidades. Segundo Azambuja (2001, p. 18) "no mundo moderno, desde que o homem nasce, e durante toda a existência, participa simultânea e

Revista Eletrônica do Alto Vale do Itajaí - REAVI, v.09, n 14, p. 082-096, ago. 2020.

ISSN: 2316-4190, DOI 10.5965/2316419009142020082 
sucessivamente de diversas instituições ou sociedades, formadas por indivíduos ligados pelo parentesco, por interesses materiais ou por objetivos espirituais". Diz ainda que os elementos essenciais do Estado são população, território e governo. Nestas linhas, ser cidadão é compor-se a uma sociedade, possuir a consciência de que é um sujeito de direitos, mas que, paralelamente a estes caminham seus deveres, de onde pega a concepção sociológica do direito de Montoro (1991, p 55), para quem esta ciência não existe a não ser para os homens vivendo em sociedade, não podendo se 'conceber uma sociedade humana em que não haja normas' jurídicas, regras, determinando as relações sociais, tal como a consciência coletiva do grupo que a representa a cada momento.

No âmbito do ordenamento constitucional brasileiro, a cidadania surge dentre os fundamentos da República Federativa do Brasil, já no seu artigo $1^{\circ}$, juntamente com "a dignidade da pessoa humana, a soberania, os valores sociais do trabalho e da livre iniciativa e o pluralismo político". No que toca aos direitos políticos, há a necessidade de conjugar esses fundamentos, principalmente a cidadania e a soberania, com o art. 14 do texto constitucional, quando o dispositivo menciona que "a soberania popular será exercida pelo sufrágio universal e pelo voto direto e secreto, com valor igual para todos, e, nos termos da lei, mediante: I - plebiscito, II - referendo e III iniciativa popular". Lenza (2007, p. 45) ensina que "além e desempenhar o poder de maneira indireta (democracia representativa) o povo também realiza diretamente concretizando a soberania popular". Diz ainda, logo a seguir, que "a CF/88 consagra a ideia de democracia semidireta ou participativa, verdadeiro sistema híbrido". Desta forma, Siqueira e Rosolen (2018, p.675) vão dizer que:

\footnotetext{
"O Brasil adotou a República Democrática, na qual o governo será exercido pelos representantes eleitos através da vontade popular. Os deveres republicanos são condições limitadoras dos representantes eleitos para satisfazer o interesse da coletividade, tendo em vista que deverão prestar contas do governo, adotar medidas transparentes e se responsabilizar politicamente pelos atos que praticar no exercício da função pública”.
}

Para Schier e Melo (2017, p. 131), “a participação popular na tomada de decisão política é uma diretriz estabelecida pelo constituinte que promove a interação entre a sociedade civil com o Estado na regulação social das políticas públicas". Os vários mecanismos de participação da Câmara Municipal de Vereadores de Cachoeira do Sul promovem esta interação à medida que muitas delas oportunizam que os cidadãos da referida municipalidade podem opinar, sugerir, questionar sobre qualquer assunto que é pautado no Parlamento do Município. Estes mecanismos aparecem neste estudo de forma quantitativa, mensurando como se efetivam, como passam a ser realidade no cotidiano das pessoas, no processo de participação social.

Bonavides (2001, p. 144) menciona que este processo compreende "a ruptura definitiva do Estado liberal e sua substituição pelo Estado social”, a consolidação do princípio democrático, onde a participação é um direito fundamental, inerente ao Estado de Direito, no ensinar de Schier e Melo (2017, p. 132).

Dentro dessa ideia, Lock (2012, p. 35) ensina que "é o direito de participação política, de decidir junto, de compartilhar a administração, opinar sobre as prioridades e fiscalizar a aplicação dos recursos públicos, confirmando, reformando ou anulando os atos públicos". Presente de forma clara esse direito de participação e colocada à disposição do cidadão as ferramentas, ou mecanismos, a esta cooperação, as escolhas políticas podem ser melhor avaliadas na promoção do

Revista Eletrônica do Alto Vale do Itajaí - REAVI, v.09, nº 14, p. 082-096, ago. 2020.

ISSN: 2316-4190, DOI 10.5965/2316419009142020082 


\section{REAVI}

desenvolvimento local, visando uma gestão eficiente, um dos princípios constitucionais da Administração Pública.

\subsection{GESTÃO PÚBLICA MUNICIPAL}

De acordo com de Barros e de Castro (2018), "a gestão pública, seja a burocrática, iniciada na segunda metade do século XIX, seja a gerencial, de 100 anos depois, é definida como a administração em instituições públicas do Estado”. Segundo Siqueira e Rosolen (2018, p. 671):

"A Administração Pública brasileira foi modificada a partir da constitucionalização do Direito Administrativo, promovendo profundas alterações na atuação da gestão pública para a sociedade; reformulou os métodos voltados ao cumprimento dos postulados constitucionais da boa Administração Pública".

Nos municípios isso foi sentido quando alcançaram o grau de autonomia que têm hoje com a Constituição de 1988, e esta autonomia, decorrente de um processo de descentralização, aparece nas repartições de competências ali descritas.

Veloso (2011, p.11) vai classificar o processo como "a redefinição do papel dos municípios brasileiros no provimento de bens e serviços públicos à população, causado principalmente pelos processos de descentralização federativa, universalização dos direitos da cidadania e instituição da seguridade social". Nesta senda, Junqueira (1998) afirma que "o desenvolvimento local é a utilização de recursos e competências locais disponíveis na busca pela melhoria da qualidade de vida da população".

No entanto, o processo crescente de urbanização tem estabelecido algumas provocações. Se por um lado, para Veloso (2011, p 13), a descentralização "seria o caminho mais adequado para aumentar a eficiência no uso dos recursos, a eficácia das políticas públicas, a transparência das decisões e a responsabilização dos governantes perante seus cidadãos", para Nahas (2016, p. 2) "a urbanização brasileira caracterizou-se pelo agravamento das desigualdades, pelo crescimento desordenado das cidades, pela degradação do meio ambiente e pelo uso predatório dos recursos naturais".

Harmonizar as oportunidades criadas pela descentralização com as responsabilidades inerentes ao aumento da autonomia e à urbanização é o desafio dos gestores, uma vez que "a gestão pública não só deve dar resposta às exigências e demandas atuais, mas também deve ser orientada ao desenvolvimento do município", sendo necessário que a gestão pública induza o processo de fortalecimento da instituição pública, como mencionado por Vidal (2016, p.191). O gestor que coloca à disposição da população mecanismos claros de participação recebe essas demandas e, nesse mesmo contexto participativo, decide junto com os administrados as políticas públicas necessárias para o desenvolvimento local e para a resolução das necessidades da população.

\section{PROCEDIMENTOS METODOLÓGICOS}

A pesquisa tem natureza exploratória com abordagem quantitativa, pois mensura as iniciativas de participação social implementadas pela Câmara Municipal de Vereadores de Cachoeira do Sul e o que foi efetivamente utilizado por sua população.

Revista Eletrônica do Alto Vale do Itajaí - REAVI, v.09, n 14, p. 082-096, ago. 2020.

ISSN: 2316-4190, DOI 10.5965/2316419009142020082 
Segundo Gil (2008, p. 27) “cada pesquisa social tem um objetivo específico”. Assim, para se chegar aos objetivos propostos neste trabalho foram utilizados como métodos, os aplicáveis à pesquisa exploratória. Para Révillion (2015, p. 22) "estudos exploratórios podem ser concebidos a partir de uma ótica objetivista, onde entram métodos, tais como os estudos de caso e grupos focais". Ao falar das finalidades desta modalidade de pesquisa, a autora completa dizendo que esta busca entende as motivações a determinadas atitudes comportamentais das pessoas. Segundo Gil (2008, p. 27), "o objetivo, na pesquisa exploratória, é proporcionar visão geral acerca de determinado fato".

Assim sendo, a pesquisa exploratória foi realizada a partir de manuais, artigos, livros e normas da municipalidade de Cachoeira do Sul, como a Lei Orgânica, o Regimento Interno da Câmara de Vereadores e suas Resoluções, relacionados ao tema, descrevendo as características de cada mecanismo de participação social e de que forma se dá a efetividade pela população da referida municipalidade. Verificando as fontes citadas, pode-se dizer que também se trata de uma pesquisa de caráter documental.

O trabalho foi organizado em cinco tópicos, os pilares para seu desenvolvimento, a saber: Introdução, pela qual o trabalho será apresentado com as razões que justificam o seu estudo; a delimitação no tempo e no espaço e qual o objetivo pretendido. $\mathrm{Na}$ fundamentação teórica a Governança, principalmente a aplicável à Administração Pública no que toca a transparência, a Democracia Participativa, pelo exercício da cidadania, e a Gestão Pública Municipal, sob o aspecto do papel do menor ente de nossa federação na elaboração de políticas públicas voltadas ao desenvolvimento e à melhora das condições de vida da população.

O item que cuida da análise e discussão dos resultados descreve como cada mecanismo de participação social da Câmara de Vereadores de Cachoeira do Sul se apresenta, como e em quantas oportunidades a sociedade fez uso desses mecanismos dentro do espaço delimitado pelo estudo, os anos de 2017 e 2018, em função do empirismo proposto. Esta análise é quantitativa visando mensurar a acessibilidade da população cachoeirense diante dos meios de participação social colocados à disposição por seu Poder Legislativo.

Nas considerações finais a análise quantitativa desses mecanismos de participação é observada a fim de que sejam verificados se os princípios e os objetos da governança pública foram alcançados.

\section{ANÁLISE DE DADOS E RESULTADOS}

Na Constituição Federal de 1988 aparecem três mecanismos de participação direta do povo, como disposto no art. 14, $4^{\circ}$, II: "a soberania popular será exercida pelo sufrágio universal e pelo voto direto e secreto, com igual valor para todos, e, nos termos da lei, mediante: I - plebiscito; II referendo; III - iniciativa popular". Nesta esteira, além das formas expressamente previstas no texto constitucional, Rocha $(2008$, p.137) ensina que "dos avanços inseridos na Constituição, quase a totalidade das políticas sociais brasileiras contam com espaços institucionalizados de participação, os conselhos, órgãos administrativos, colegiados com representantes da sociedade civil e do poder pública". Como já mencionado, esses avanços no que toca a participação cidadã alcançaram os municípios também.

Delimitado no espaço, o estudo abordará a realidade no município de Cachoeira do Sul, da região central do Rio Grande do Sul, com população estimada em 82.547 habitantes. $\mathrm{O}$ artigo $1^{\circ}$ da

Revista Eletrônica do Alto Vale do Itajaí - REAVI, v.09, n 14, p. 082-096, ago. 2020.

ISSN: 2316-4190, DOI 10.5965/2316419009142020082 
sua Lei Orgânica, promulgada em maio de 1990, diz que "reger-se-á observados os princípios estabelecidos nas Constituições Federal e Estadual". Diz ainda a "lei máxima" do município que poderá ser emendada mediante proposta dos eleitores, subscrita, no mínimo, por cinco por cento dos eleitores do Município ${ }^{1}$. Além da possibilidade dos eleitores modificarem a lei orgânica a estes também cabe a iniciativa das leis ${ }^{2}$. No que toca o poder popular ${ }^{3}$, ainda tem a previsão do acesso à informação, à tribuna popular ${ }^{4}$, cuja utilização vem disciplinada no Regimento Interno do Legislativo, e a garantia das consultas referendárias, plebiscitárias ou revogatórias, por cinco por cento do eleitorado do Município. Também, na norma procedimental interna da Casa que vem a previsão das audiências públicas ${ }^{5}$. Ainda inserido no processo legislativo, previsto na Lei Orgânica, da referida municipalidade, aparecem as resoluções, previstas no art. $2^{\circ}, \S 1^{\circ}, \mathrm{V}$, Regimento Interno da Câmara Municipal, como uma de suas funções legislativas. Estas resoluções se apresentam de várias formas e finalidades:

a) Ouvidoria: Criada pela Resolução 05/02, de 26 de fevereiro de 2002, entre seus objetivos está propiciar à comunidade um meio de manifestar os seus pedidos, reclamações, apoio e reivindicações à ação dos vereadores e da Administração Municipal e a ampliação dos canais de participação da comunidade junto ao Poder Legislativo. O ouvidor recebe as demandas e dá os encaminhamentos de acordo com os destinatários. São instrumentos aos trabalhos e ao funcionamento da Ouvidoria ${ }^{6}$, a urna ${ }^{7}$, tribuna livre, os pedidos que lhe forem encaminhados diretamente, o atendimento direto ao público e os requerimentos formalizados pelos vereadores;

b) Tribuna do Estudante: Instituída pela Resolução 03/04, de 08 de junho de 2004, é o instrumento que o Poder Legislativo utilizará para possibilitar a participação dos estudantes na discussão dos assuntos de interesse da comunidade e, ao mesmo tempo, incentivar a criação de novos líderes entre os jovens cachoeirenses. Consiste na realização de cinco reuniões durante o ano letivo, com a participação dos Vereadores e Estudantes, os quais terão a oportunidade de se manifestar sobre o assunto em pauta;

c) Fala Comunidade e Fala Interior: Criados pela Resolução 01/05, de 09 de março de 2005, a iniciativa tem por objetivo promover reuniões descentralizadas da Câmara de Vereadores, respectivamente, com as comunidades da zona urbana e rural de Cachoeira do Sul, a fim de colher propostas, ideias, sugestões, críticas e informações relativas à realidade do município, e dar os encaminhamentos cabíveis em forma de proposição conforme o estabelecido no Regimento Interno da Casa;

\footnotetext{
${ }^{1}$ Art. 32, III, $\$ 2^{\text {o }}$;

${ }^{2} \mathrm{O}$ art. 35 diz que exercerá em forma de moção articulada, subscrita, no mínimo, por cinco por cento do eleitorado do Município, da cidade, do bairro ou comunidade rural, conforme o interesse ou abrangência da proposta.

${ }^{3}$ Artigos 62 a 64 da Lei Orgânica;

${ }^{4}$ Prevista no art. 105 do Regimento Interno, e disciplinada pelos artigos 199 a 203.

${ }^{5} \mathrm{O}$ art. 204 diz que as Comissões poderão realizar audiências públicas, inclusive com entidades da sociedade civil e Conselhos Populares, para instruir matéria em tramitação de seu âmbito regimental de atuação, bem como para tratar de assunto de interesse público, a critério da Comissão.

${ }^{6}$ Art. $4^{\circ}$ da Resolução 05/02, de 26 de fevereiro de 2002;

${ }^{7}$ Utilizada principalmente quando a Câmara de Vereadores se faz presente em eventos abertos ao público. É colocada no local e fica à disposição da população que, através de formulários, encaminham suas demandas ao Legislativo. Esses pedidos serão encaminhados através de pedidos de providência, de informações ou indicações, de acordo com a natureza;
}

Revista Eletrônica do Alto Vale do Itajaí - REAVI, v.09, nº 14, p. 082-096, ago. 2020.

ISSN: 2316-4190, DOI 10.5965/2316419009142020082 
d) Câmara Estudantil Cachoeirense: Estabelecida pela Resolução n ${ }^{\circ}$ 03/05 de 03 de agosto de 2005, objetiva a participação das lideranças estudantis do município de forma a propiciar a estas o conhecimento do trabalho parlamentar, através da simulação de etapas do processo legislativo, em especial nas sessões plenárias. Composta pelo mesmo número de Vereadores da Casa, 15, será composta por Presidentes de Grêmios Estudantis ou seus representantes;

e) Câmara nas Escolas: Implementada pelo Decreto Legislativo 02, de 2 de junho de 2009, o projeto tem por objetivo levar a Câmara de Vereadores às Escolas sediadas no Município para aprimorar os conhecimentos dos estudantes acerca do Poder Legislativo, realizando palestras que propiciem aos alunos o conhecimento do trabalho, estrutura e funções do mesmo.

A tabela abaixo mostra, de forma bem didática, como os instrumentos de participação social da Câmara de Vereadores de Cachoeira do Sul foram demandados do ponto de vista quantitativo. Inobstante, algumas considerações, que seguirão à tabela, são importantes para uma melhor análise do quadro:

Quadro 01 - Mecanismos de Participação.

\begin{tabular}{|l|c|c|c|}
\hline \multicolumn{1}{|c|}{ Mecanismo de Participação } & $\mathbf{2 0 1 7}$ & $\mathbf{2 0 1 8}$ & Total \\
\hline Proposta de Emenda à Lei Orgânica & - & - & - \\
\hline Lei de Iniciativa Popular & - & - & - \\
\hline $\begin{array}{l}\text { Consultas referendarias, plebiscitárias ou } \\
\text { revogatórias }\end{array}$ & - & - & \\
\hline Tribuna Popular & 35 & 24 & 59 \\
\hline Audiência Pública & 09 & 18 & 27 \\
\hline Ouvidoria & - & 22 & - \\
\hline Tribuna do Estudante & - & - & - \\
\hline Fala Comunidade & - & - & 06 \\
\hline Fala Interior & 03 & 03 & - \\
\hline Câmara Estudantil & - & - & 09 \\
\hline Câmara nas Escolas & 06 & 03 & \\
\hline
\end{tabular}

Fonte: elaborado pelos autores.

De todos os instrumentos de participação sociais disponíveis pelo Legislativo cachoeirense, o mais utilizado no período a que o estudo se propôs é a tribuna popular (mais que o dobro do segundo colocado, a audiência pública). É de creditar esse índice à forma relativamente simples de acesso a este mecanismo de participação ${ }^{8}$, onde sindicatos, entidades representativas de moradores, Conselhos Populares, associações de categorias profissionais, munícipe com trabalho relevante ou entidade representativa da sociedade civil, desde que convidado(s) por vereador, para melhor explicar suas atividades, através de ofício à Presidência da Casa, contendo os dados de identificação da entidade, o nome do orador e o assunto a ser tratado, poderão se manifestar pelo tempo de 10 (dez) minutos, na quinta parte das sessões ordinárias ${ }^{9}$; Entender as razões que levaram cerca de 60 (sessenta pessoas), em dois anos, a ocuparem a tribuna do seu Legislativo para falarem aos seus

\footnotetext{
${ }^{8}$ Artigos 200 e 201 do Regimento Interno da Câmara de Vereadores de Cachoeira do Sul

${ }^{9}$ O artigo 99 do Regimento Interno divide a sessão ordinária em 10 (dez) partes: I - à discussão e votação da ata; II - à leitura do expediente; III - à leitura de um trecho da Bíblia Sagrada; IV - ao Pequeno Expediente; V - à Tribuna Popular; VI - ao Grande Expediente; VII - à apresentação e discussão de proposições em pauta; VIII - à discussão e votação da matéria da ordem do dia; IX - às comunicações da Presidência; X - às Explicações Pessoais.
}

Revista Eletrônica do Alto Vale do Itajaí - REAVI, v.09, n 14, p. 082-096, ago. 2020.

ISSN: 2316-4190, DOI 10.5965/2316419009142020082 
representantes na municipalidade demandaria a coleta de entrevistas para a qual este estudo não se propôs, deixando espaço a outros trabalhos que mediriam, qualitativamente, essas iniciativas.

Audiências públicas foram a segunda forma mais utilizada de participação social durante o tempo estudado, onde os mais variados assuntos foram discutidos. Colaboraram para o número, nos dois anos os encontros dispostos nas leis orçamentárias. O artigo 48 da Lei de Responsabilidade Fiscal (LRF - Lei Complementar 101/00) estabelece parâmetros acerca da transparência nos gastos públicos, onde uma das formas é a realização de audiências quadrimestrais com participação popular para demonstração dos anexos pertencentes à Gestão Fiscal e Execução Orçamentária. Buscando ampliar a compreensão e a participação popular, a Lei Complementar 131/09, que incluiu o inciso I ao artigo 48 da LRF, incentivando a participação popular disciplinou a realização de audiências públicas, durante os processos de elaboração e discussão dos planos, lei de diretrizes orçamentárias e orçamentos. Um fator determinante para que o segundo ano do estudo houvesse grande aumento no número de audiências públicas foi a realização de 7 (sete) encontros descentralizados ${ }^{10}$, de 14 agosto a 11 de setembro, para que a Câmara de Vereadores pudesse ouvir a população sobre o Projeto de Lei $n^{\circ}$ 22/2018, de autoria do Executivo que alteraria a Planta Genérica de Valores do Município de Cachoeira do Sul. Na sessão do dia 17 de setembro o projeto foi rejeitado por unanimidade, uma vez que nos encontros a população se manifestou majoritariamente contrária à proposta.

Propostas populares, de Emenda à Lei Orgânica, de Lei ou Consultas referendárias, plebiscitárias ou revogatórias, não foram experimentadas no período compreendido no estudo. Apenas uma vez, na história recente da municipalidade, uma iniciativa dessas foi levada a efeito quando, em 2012, liderados pela Câmara do Comércio, Indústria e Serviço de Cachoeira (Cacisc) houve tentativa de mitigar a composição do Legislativo Municipal, de 15, aprovada pela Emenda à Lei Orgânica $\mathrm{n}^{\circ} 05$, de 06 de julho de 2011, para 10 cadeiras $^{11}$. O processo, eivado de vícios formais, teve seu fim pela decisão, do Tribunal de Justiça do Estado do Rio Grande do Sul, nos autos do Agravo de Instrumento ${ }^{\circ}$ 70048843718, de 14 de agosto de $2013^{12}$. Apesar disso, é de referir o entendimento de Harlet, da Silveira e Alves (2016, p.352), para quem "a participação ativa do povo brasileiro nas decisões politicas é ainda incipiente. Não por falta de anseios populares, mas pelos critérios trazidos no texto constitucional". Sobre isso Silva (2011, p. 121) nos ensina que "a legalidade é também um princípio basilar do Estado Democrático de Direito. É essência do seu conceito subordinar-se à Constituição e fundar-se na legalidade democrática". E segue, completando o raciocínio, quando diz que "o direito, então, imanado por esses valores, se enriquece do sentir popular e terá que ajustar-se ao interesse coletivo".

A Ouvidoria, muito embora exista desde 2002, não existem registros dos seus trabalhos em 2017, vindo a ser reimplementada no ano seguinte, a partir de divulgação desse instrumento de interação com a comunidade. Quanto aos demais mecanismos de participação maior destaque não merecem, pois não destoam da rotina do Parlamento Municipal. As ausências sentidas quanto à Tribuna do Estudante, o Fala Comunidade e a Câmara Estudantil, diante da demanda de trabalho, estes mecanismos não puderam ser experimentados.

\footnotetext{
${ }^{10}$ A cidade foi dividia em 7 regiões para que toda a população pudesse participar;

${ }^{11}$ Maiores detalhes podem ser acessados nas edições de 09 de novembro de 2011 e 01 de agosto de 2012 do Jornal do Povo, disponíveis em https://www.jornaldopovo.com.br/site/index.php, acessadas em: jul 2019

${ }^{12}$ Disponível em http://www.tjrs.jus.br/busca/?tb=proc, acessado em: jul 2019, na aba processos no Tribunal de Justiça; Revista Eletrônica do Alto Vale do Itajaí - REAVI, v.09, nº 14, p. 082-096, ago. 2020.
}

ISSN: 2316-4190, DOI 10.5965/2316419009142020082 
Quando verificado como tudo isso se operou no contexto local, observa-se a avaliação feita pelo Tribunal de Contas do Estado do Rio Grande do Sul (TCE-RS) no tocante à transparência. A preocupação da governança pública com a gestão dos recursos públicos de que falam Pinto e Reisdorfer (2015, p. 30), encontra justificativa quando as preocupações levantadas por Ckagnazaroff (2017) se materializam na busca pela eficiência com a transparência e prestação de contas. Assim é que a referida Corte de Contas realizou avaliação dos sites dos Executivos e Legislativos Municipais do Estado do Rio Grande do Sul, no período de 06/08/2018 a 11/10/2018. A Câmara Municipal de Cachoeira do Sul fez uso do prazo dado pelo Tribunal, de 15/10/2018 a 26/10/2018, para solicitar revisão à avaliação e dos 31 pedidos, 22 foram deferidos ${ }^{13}$, resultando no preenchimento de 49 itens, dos 59 avaliados pelo TCE gaúcho no quesito transparência, elevando este patamar a $83 \%$ de atendimento $^{14}$. No ano anterior, 2017, com o preenchimento de 37 dos mesmos 59 itens o atendimento era de $62 \%$.

\section{CONSIDERAÇÕES FINAIS}

Descrever e analisar mecanismos de participação social no âmbito de uma Casa Legislativa é tarefa instigante, que aumenta à medida que se está, neste ambiente, exercendo mandato parlamentar. A proposta empírica norteadora do presente trabalho se deu neste sentido. Ao lado de toda a fundamentação teórica foi possível compreender de forma mais ampliada como cada processo de participação acontece e onde se justifica, onde a cidadania ativa é decorrente de um processo de consolidação e maturação desse princípio inerente ao estado democrático de direito. O cenário nacional e internacional, quando a gestão pública deixa de ser burocrática e passa à postura gerencial têm espaço para esta institucionalização à medida que as gestões públicas, independentemente do nível de governo estão envoltas a questões que envolvem eficiência e a eficácia nas suas atuações, de quem a preocupação com a transparência, prestação de contas e a legitimidade andam paralelamente.

Emerge desse processo o conceito de governança que, inicialmente trazido da iniciativa privada, na sua forma corporativa, gradativamente ganha espaço junto aos órgãos públicos a ponto de a governança pública receber significativa atenção da academia, de forma a ser compreendida como as condições que o setor público tem em formular e programar políticas públicas tendentes ao atendimento das demandas e metas da coletividade, sem deixar de atentar à correta gestão do dinheiro público. Com o aumento significativo da autonomia dos municípios, trazida pela Constituição Federal de 1988, cresce a responsabilidade dos agentes políticos locais, sejam prefeitos, na sua função típica de administrar a cidade, sejam dos parlamentares, no seu mister de legislar e fiscalizar, na redefinição deste, que é o menor ente de nossa federação no provimento de bens e serviços públicos à população.

O desenvolvimento dessas unidades federativas dar-se-á à medida que for melhor a utilização de recursos, bem como as competências locais disponíveis, os stakeholders da cidade puderam ser melhores utilizadas na busca pela melhoria da qualidade de vida da população como

${ }^{13}$ Disponível em: http://portal.tce.rs.gov.br/docs/transparencia_2018/relatorio_transparencia_2018.pdf. Acesso em jul: 2019.

${ }^{14}$ Disponível em: https://portal.tce.rs.gov.br/portal/page/portal/tcers/publicacoes/estudos/avaliacao_portais_rs. Acesso em jul: 2019

Revista Eletrônica do Alto Vale do Itajaí - REAVI, v.09, n 14, p. 082-096, ago. 2020.

ISSN: 2316-4190, DOI 10.5965/2316419009142020082 
um todo. Essa melhoria pode se dar não somente na forma tradicional de representação, típica do Estado Moderno, mas em todos os fóruns de exercício da cidadania, bastando que exista um ambiente institucional acessível e transparente a este protagonismo. Durante este estudo foi possível verificar a compatibilidade de todos os fundamentos do referencial teórico ao contexto verificado na unidade estudada, ou seja, a Câmara Municipal de Vereadores de Cachoeira do Sul, nos anos de 2017 e 2018. A busca pela implementação dos princípios norteadores da governança pública, aliada às ferramentas constantes da democracia representativa e da gestão pública municipal se evidenciou pela avaliação do Tribunal de Contas do Estado do Rio Grande do Sul que reconheceu avanços, de um ano para outro, no que toca a divulgação de informações no portal da transparência do Legislativo Municipal em apreço.

\section{REFERÊNCIAS}

AVRITZER, Leonardo (Org.). Experiência democrática, sistema político e participação popular / Leonardo Avritzer. - São Paulo: Editora Fundação Perseu Abramo, 2013.

BONAVIDES, Paulo. Teoria Constitucional da Democracia Participativa. São Paulo: Malheiros, 2001.

BRASIL - Constituição Federal de 1988. Disponível em

http://www.planalto.gov.br/ccivil_03/constituicao/constituicao.htm, Acesso em jul. 2019.

- Lei Complementar 101/00 - Lei de Responsabilidade Fiscal. Disponível em:

http://www.planalto.gov.br/ccivil_03/leis/lcp/lcp101.htm, Acesso em jul. 2019.

- Lei Complementar 131/09 - Lei da Transparência, Disponível em:

http://www.planalto.gov.br/ccivil_03/leis/lcp/lcp131.htm, Acesso em jul. 2019.

CACHOEIRA DO SUL - Lei Orgânica do Município. Disponível em:

https://www.camaracachoeira.rs.gov.br/index.php/legislao-mainmenu-33. Acesso em jul. 2019.

- Decreto Legislativo 02/09, da Câmara de Vereadores de Cachoeira

do Sul, de 2 de junho de 2009, que criou o projeto Câmara nas Escolas no âmbito do Poder Legislativo Municipal. Disponível em: https://www.camaracachoeira.rs.gov.br/index.php/legislaomainmenu-33. Acesso em jul. 2019.

- Resolução 16/91 - Regimento Interno da Câmara de Vereadores de

Cachoeira do Sul. Disponível em: https://www.camaracachoeira.rs.gov.br/index.php/legislaomainmenu-33. Acesso em jul. 2019.

- Resolução 05/02, da Câmara de Vereadores de Cachoeira do Sul, de

26 de fevereiro de 2002, que criou a Ouvidoria no âmbito do Poder Legislativo Municipal. 
Disponível em: https://www.camaracachoeira.rs.gov.br/index.php/legislao-mainmenu-33. Acesso em jul. 2019.

- Resolução 03/04, da Câmara de Vereadores de Cachoeira do Sul, de 08 de junho de 2004, que criou a Tribuna do Estudante no âmbito do Poder Legislativo Municipal. Disponível em: https://www.camaracachoeira.rs.gov.br/index.php/legislao-mainmenu-33. Acesso em jul. 2019.

- Resolução 01/05, da Câmara de Vereadores de Cachoeira do Sul, de de 09 de março de 2005, que criou os Projetos Fala Comunidade e Fala Interior no âmbito do Poder Legislativo Municipal. Disponível em: https://www.camaracachoeira.rs.gov.br/index.php/legislaomainmenu-33. Acesso em jul. 2019.

- Resolução 03/05, da Câmara de Vereadores de Cachoeira do Sul, de 03 de agosto de 2005, que criou a Câmara Estudantil no âmbito do Poder Legislativo Municipal. Disponível em: https://www.camaracachoeira.rs.gov.br/index.php/legislao-mainmenu-33. Acesso em jul. 2019.

CANÇADO, Airton Cardoso; PEREIRA, José Roberto; TENÓRIO, Fernando Guilherme. Fundamentos Teóricos da Gestão Social/Fundamentos de la gestión social: una aproximación teórica/Theoretical foundations of the social management. Desenvolvimento Regional em debate: DRd, v. 5, n. 1, p. 4-19, 2015.

CKAGNAZAROFF, Ivan Beck. A relação entre gestão de política pública e governança. GIGAPP Estudios Working Papers, v. 4, n. 72-78, p. 345-359, 2017.

DE BARROS, Aluízio Antônio; DE CASTRO, Carlos Henrique Silva. Gestão social e gestão pública no desenvolvimento local. Cadernos do Desenvolvimento, v. 8, n. 12, p. 147-162, 2018.

HARET, Florence Cronemberger Haret; DA SILVEIRA, Daniel Barile; ALVES, Edmilson Pereira. Governança corporativa e soberania popoular: Mecanismo de controle do poder do Estado na Sociedade e Economia. Economic Analysis of Law Review, v. 6, n. 2, p. 333-355, 2016.

INSTITUTO BRASILEIRO DE GOVERNANÇA CORPORATIVA (IBGC). Código das Melhores Praticas de Governança Corporativa. 4.ed. / Instituto Brasileiro de Governança Corporativa. São Paulo, SP: IBGC, 2009.

INSTITUTO BRASILEIRO DE GEORGRAFIA E ESTATÍSTICA (IBGE) - Censo de 2018. Disponível em: https://cidades.ibge.gov.br/brasil/rs/cachoeira-do-sul/panorama, acesso em jul. 2019.

LENZA, Pedro. Direito constitucional esquematizado®. Editora Saraiva, 2007. 


\section{REAVI}

LOCK, F. do N. Estrutura e uso de informações orçamentárias governamentais: o caso do Conselho Municipal de Educação de Santa Maria-RS. 2012. 267 f. 2012. Tese de Doutorado. Tese (Doutorado em Desenvolvimento Regional)-Universidade de Santa Cruz do Sul, Santa Cruz do Sul.

NAHAS, Maria Inês Pedrosa et al. Sistemas de Indicadores Municipais no Brasil: experiências e metodologias. Anais, p. 1-17, 2016.

NOBRE, Carla Janaina Ferreira et al. A condição financeira governamental e sua influência na transparência da gestão pública municipal. 2017.

PINTO, Nelson Guilherme Machado; REISDORFER, Vitor Kochhann. Governança cooperativa. Universidade Federal de Santa Maria, Colégio Politécnico, Rede e-Tec Brasil, Santa Maria/RS, 2015.

RAMOS, Schirlei Stock; VIEIRA, Kelmara Mendes; PARABONI, Ana Luiza. Governança Corporativa em Organizações Públicas: Aplicação do Limpe na Mesorregião CentroOcidental Rio-Grandense. Revista Administração em Diálogo-RAD, v. 19, n. 1, p. 01-31, 2017.

RÉVILLION, Anya Sartori Piatnicki. A utilização de pesquisas exploratórias na área de marketing. Revista Interdisciplinar de Marketing, v. 2, n. 2, p. 21-37, 2015.

RIO GRANDE DO SUL - Tribunal de Contas do Estado do Rio Grande do Sul. Relatório da Transparência de 2018. Disponível em:

http://portal.tce.rs.gov.br/docs/transparencia_2018/relatorio_transparencia_2018.pdf. Acesso em jul. 2019.

ROCHA, Enid. A Constituição Cidadã e a institucionalização dos espaços de participação social: avanços e desafios. VAZ, Flavio Tonelli; MUSSE, Juliano Sander; SANTOS, Rodolfo Fonseca (Coords.), v. 20, p. 131-148, 2008.

RODRIGUES, Marlene; DALONGARO, Roberto. Governança corporativa. Observatorio de la Economía Latinoamericana, n. abril, 2018.

SCHIER, Adriana da Costa Ricardo; MELO, Juliane Andrea de Mendes Hey. O direito à participação popular como expressão do Estado Social e Democrático de Direito. A\&C Revista de Direito Administrativo \& Constitucional, Belo Horizonte, ano 17, n. 69, p. 127-147, jul./set. 2017.

SILVA, José Afonso da. Curso de direito constitucional positivo. Revista e atualizada (até a EC 67, de 22.12.2010). São Paulo: Malheiros, 2011. 


\section{REAVI}

SIQUEIRA, Dirceu Pereira; ROSOLEN, André Vinícius. Governança do Estado e o Direito (Dever) à boa Administração Pública: A Regra da Observância aos Preceitos Constitucionais. Revista Argumentum-Argumentum Journal of Law, v. 18, n. 3, p. 665-678, 2018.

SOBREIRA, Karoline Rodrigues; JÚNIOR, Manuel Salgueiro Rodrigues. Governança no setor público segundo IFAC: levantamento do nível de aderência de uma instituição de ensino superior. Revista Controle: Doutrinas e artigos, v. 15, n. 1, p. 166-194, 2017.

VELOSO, João Francisco Alves Organizador et al. Gestão municipal no Brasil: um retrato das prefeituras. 2011.

VIDAL, Josep Pont; DE SOUZA ROSA FILHO, Duarte. Desafios de uma nova gestão pública para o desenvolvimento dos municípios no Pará. Novos Cadernos NAEA, v. 14, n. 2, 2016. 